Research Article

\title{
Dynamic Modeling and Analysis of the Telescopic Sleeve Antiswing Device for Shipboard Cranes
}

\author{
Jianli Wang $\mathbb{D},{ }^{1,2}$ Shenghai Wang $\mathbb{D},{ }^{1}$ Haiquan Chen $\mathbb{D}^{1},{ }^{1}$ Anqi Niu $\mathbb{D}^{1},{ }^{1}$ and Guoliang Jin $\mathbb{D}^{1}$ \\ ${ }^{1}$ College of Marine Engineering, Dalian Maritime University, Dalian 116026, China \\ ${ }^{2}$ Bohai Shipbuilding Heavy Industry Co., Ltd., Huludao 125004, China \\ Correspondence should be addressed to Shenghai Wang; shenghai_wang@dlmu.edu.cn
}

Received 10 December 2020; Revised 6 February 2021; Accepted 10 February 2021; Published 19 February 2021

Academic Editor: Krzysztof Kecik

Copyright (c) 2021 Jianli Wang et al. This is an open access article distributed under the Creative Commons Attribution License, which permits unrestricted use, distribution, and reproduction in any medium, provided the original work is properly cited.

In order to explore the dynamic characteristics of the telescopic sleeve antiswing device for shipboard cranes under coupling excitation, a three-dimensional dynamic model of the ship crane telescopic sleeve antiswing device is established in this study, and the accuracy of the model is verified through experiments. By dynamic analysis, the influence of sleeve extension and contraction, damper parameters, and ship excitation on the payload swing is found; meanwhile, the influence of payload swing on ship stability is discovered. At the same time, the simulation results show that the three-dimensional dynamic model can accurately simulate the swing reduction characteristics of the antiswing device. The in-plane and out-plane angles of the swing are reduced by $70 \%$ and $90 \%$. The research results have great significance to further explore the antiswing mechanism and structural design of the mechanical antiswing device.

\section{Introduction}

For shipboard crane systems, the payload swing might be induced by the coupling effect of the ship motions and crane movements. Shipboard cranes are typical nonlinear, strong coupling, underactuated systems [1]. In engineering practice, antiswing control is particularly important. Special vessels such as pipe-laying ships, windmill installation ships, crane ships, and other special ships have high requirements for antiswing control during offshore operations $[2,3]$. The shipboard crane system involves the combination of various disciplines and is very complex, especially the research on antiswing control during cargo handling operations.

Dynamic modeling of the shipboard cranes with wave compensation is an important aspect of the research on various cranes. Wave compensation is mainly divided into three categories: passive compensation [4-6], active compensation [7-9], and semiactive compensation [10-12]. Wave compensation [13-15] is the earliest technology applied to ensure the safety of ships at sea in severe weather [16]. In order to ensure the compensation of marine equipment under wave motion, certain technical measures need to be taken to counter external interference. Jardim et al. [17] analyzed the motion of a ship induced by an onboard crane in operation using the moving frame method (MFM). This method together with a compact notation from geometrical physics makes it possible to extract the equations of motion, expeditiously. Rong et al. [18] proposed a discrete time transfer matrix method of the multibody system for dynamics modeling and analysis of a ship's seaborne supply system, and this method solves the dynamics of the system easily only by the low-order transfer equations, instead of the usual high-order global differential or differential-algebra equations of the system. Nguyen et al. [19] proposed the modeling and a control design based on integral hierarchical sliding mode control structure for a $2 \mathrm{D}$ offshore crane. The container crane mounted on a ship is taken into consideration, and its modeling is derived using the Lagrange formulation. Li et al. [20] established the mathematical model of the load, and based on a timedelayed feedback, the control algorithm was proposed to antiload sway. Wang et al. [21] proposed a novel offshore crane combined compensation approach named four-post combined compensation based on the three-post direct ship 
motion compensation; the mathematical models of fourpost combined compensation and three-post direct ship motion compensation were established uniformly. Lv et al. [22] designed a 6-DOF active wave compensation cabledrive parallel robot that established its kinematic and dynamic model and explored swing suppression principle of the robot. Mao [23] proposed an antiswing control method based on steady-state feedback compensation regulation. The antiswing control constraint parameter model of shipboard crane was constructed, and the swing amplitude, rotational moment, and inertia moment were used as feedback adjusting parameters to compensate the steadystate error of shipboard crane. Li and Qiu [24] carried out dynamic analysis of the nonlinear relationship of the parallel four-bar mechanism consisting of an electric cylinder, a crane jib, and a superstructure and established the mechanical equations, kinematic equations, and dynamic equations for simplified physical models of shipboard crane. Han et al. [25] designed a kind of the sling tray antiswing device, which reduced the length of the lifting rope to reduce the swing of payload. The kinematic equations of the payload were established under the condition of whether the antiswing device was provided, and the dynamic analysis was carried out in Matlab/Simulink environment. Sun et al. [26] presented a novel nonlinear stabilizing control strategy for underactuated ship-mounted crane systems, which without linearizing the original nonlinear dynamics when performing controller design and stability analysis, for underactuated ship-mounted cranes with ship roll and heave movements. Chin et al. [27, 28] regarded the shipboard crane as a space ball pendulum with foundation excitation, established the dynamic model, and studied the stability of the hoisting system under the conditions of excitation and parameter changes.

Crane antiswing control is mainly divided into two methods: electronic antiswing and mechanical antiswing. Among them, electronic antiswing adopts mechatronics technology, which achieves the purpose of payload swing reduction by controlling the crane movement speed and direction using various sensors and detection devices to measure the motion of the ship, crane, and payload. Mechanical antiswing is to reduce the swing by consuming the energy of payload swing by the mechanical method. For the above two antiswing methods, many studies have been conducted by scientific researchers [29-40].

The electronic antiswing method usually combines computers, sensors, and motors into a system, but the complex control system greatly increases the cost of the crane system and energy consumption of the control process. Ngo et al. [29] investigated the problem of payload pendulation and container position for an offshore container crane using an adaptive-gain sliding mode control (SMC) scheme. Yang et al. [30] designed a neural network-based adaptive control method, which is based on a $2 \mathrm{D}$ sliding surface. The boom and rope of ship-mounted crane could arrive at their preset positions in finite time, and the payload swing could be completely suppressed. Tuan et al. [31] presented a design of two nonlinear robust controllers, taking into account the influence of the output hysteresis and using velocity feedback from a state observer. Tuan et al. [32] proposed a robust adaptive system for a ship-mounted container crane. The controller structure was constructed using second-order sliding mode control (SOSMC), and a modeling estimator was designed on the basis of the radial basis function network (RBFN). Qian et al. [33] proposed a novel nonlinear energy-based coupling control for an underactuated offshore ship-mounted crane which guaranteed asymptotic stability of the crane control system's equilibrium point. Qian et al. [34] studied the adaptive robust tracking control problem for an offshore shipmounted crane and proposed a new adaptive robust coupling control approach, with adaptive laws included to deal with unknown parameters and robust terms included to handle unknown disturbances, especially unmatched disturbances, which achieved simultaneous load swing suppression and disturbances elimination. Tuan et al. [32] proposed a robust adaptive system for the highly underactuated nonlinear characteristics of offshore container cranes and verified the superiority of the proposed control system. Nguyen et al. [35] proposed a fuzzy sliding mode control (FSMC) method, which uses fuzzy rules to adjust the parameters of the sliding mode controller in real time. Under the random roll motion excitation, the payload swing is effectively suppressed to a small range. $\mathrm{Wu}$ [36] proposed a nonlinear controller for ship crane and developed an improved antiswing tracking controller to achieve both precise trolley positioning and sufficient payload swing elimination and proved the stability of the closed-loop system. Panuncio et al. [37] combined neural networks with the PID controller to realize crane antiswing control. They proved the semiglobal asymptotic stability of the controller and verified the effectiveness of the method through crane model experiments. Wang and Qiu [38] proposed a fuzzy control method for bridge cranes and established an accurate two-dimensional bridge crane model with variable rope length under the action of damping force; based on the design of appropriate fuzzy rules, a fuzzy adaptive PID controller is constructed to realize the antipendulum positioning control of bridge crane. Yang et al. [39] designed a neural network-based adaptive control method that can provide effective control for both actuated and unactuated state variables based on the original nonlinear ship-mounted crane dynamics without any linearizing operations, the boom and rope can arrive at their preset positions in finite time, and the payload swing can be completely suppressed. Sun et al. [40] proposed a first input-saturated control method that include nonlinear coupling terms to realize the objective of effective positioning and swing suppression without the requirement of velocity feedback.

The most common approach of crane mechanical antiswing is to control the payload swing by taglines. This method has relatively higher requirements for ship deck space and needs to consider the rubbing wear of taglines. Ren et al. [41] proposed a mechanical antiswing device based on triple-cables limiting-location. Three cables were used to pull the hook, which limited the spatial position of the payload to prevent the payload pendulation, and the overall antiswing effect could reach more than 61\%. van Albada 
et al. [42] proposed a mechanical control device based on energy dissipation, which can reduce the influence of fluctuation in three-dimensional space and at the same time reduce the wave impact during the working process of ship crane. The simulation results confirm the principle and the effectiveness of the proposed method. Wang et al. [43] proposed a triple-tagline mechanical antiswing device, which has been tested by experiments with a good behavior of payload swing suppression. Chen and Wang [44] invented a telescopic sleeve antiswing device for shipboard cranes. Han et al. [45] further built a simulation model by Adams and carried out kinetics analysis of this device to verify its effectiveness. Cao and $\mathrm{Li}$ [46] presented a brief review on modeling and dynamics analysis to illustrate the tremendous challenges and difficulties in controller design for shipboard cranes; a comprehensive review and brief analysis of shipboard crane control strategies are further presented, and some future research directions are also put forward. The Maryland Rigging system was first proposed by Hunt and Yuan; further research studies were carried out by many scholars such as Kimiahalam et al. developing various control systems and compensation systems [47-50].

Establishing an accurate dynamic model is critical to evaluate and predict the performance of the antiswing device for shipboard cranes. The research contents of abovementioned literature concentrates on kinematic characteristics and experimental analysis of the antiswing device, while the more profound research on three-dimensional dynamic modeling and analysis is needed. In this study, a 3D dynamic model is established for the telescopic sleeve antiswing device and verified through experiments. The simulation analysis is carried out to further investigate the device's dynamic characteristics. The response law of inplane angle and out-plane angle under different working conditions is discovered. The research results of this study can provide theoretical basis for the design of shipboard antiswing devices and can be used as reference by engineers and technicians.

\section{Structure of the Telescopic Sleeve Antiswing Device}

As shown in Figure 1, the telescopic sleeve antiswing system has the advantages of simple structure, small space ratio, low cost, and the good energy consumption effect. The sleeve telescopic antiswing device is similar to a passive vibration reduction system. The principle of the device can be explained as follows: when the payload swing is induced by the coupling excitations of crane base motions and crane boom movements, the payload pushes the sleeve to rotate about the spherical joint, and then, the spring dampers would restrict the relative motions of the payload. As a result, the kinetic energy of the payload swing is consumed, and the objective of payload swing reduction is realized.

\section{Dynamic Model}

In this study, the elements of the shipboard crane system are regarded as rigid bodies. The payload is regarded as a mass

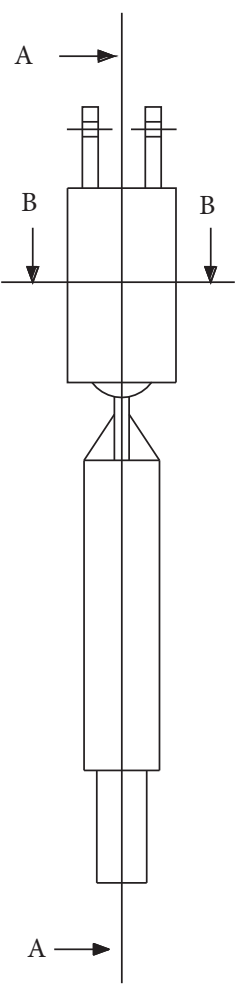

Section A-A

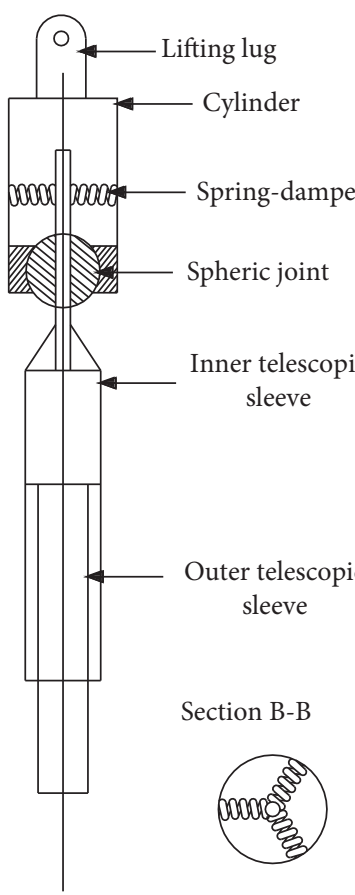

Figure 1: Telescopic sleeve antiswing device.

point, and the diameter of the antiswing device is ignored. The simplified model of the system including the ship, crane base, crane boom, antiswing device, and payload is shown in Figure 2. The global coordinate system $O_{0 x 0 y 0 z 0}$ is fixed in the flow field which does not move with the hull. The ship-based coordinate system is $O_{1 \times 1 y 1 z 1}$, which moves and rotates with the hull. When the ship is in equilibrium position, the origin of $O_{1 \times 1 y 1 z 1}$ coincides with the ship gravity center. The crane boom coordinate system is $O_{2 x 2 y z z 2}, x$ axis is parallel to the keel plate of the hull, which points to the bow, $y$ axis refers to ship mould breadth direction, pointing to the starboard side, $z$ axis represents the depth direction, vertically upward, $\theta_{1 x}$ is the ship's roll angle, $\theta_{2 z}$ is the crane rotation angle, $\theta_{2 y}$ is the crane boom luffing angle, and $\psi_{1}$ and $\psi_{0}$ represent the inplane angle and out-plane angle of the payload swing, respectively.

3.1. Description of Ship Rotation Attitude. The rotation attitude of the ship is described by the rotation of the shipbased coordinate system, and the angular displacement can be defined by three Euler angles [51]. These three rotation angles completely determine the space attitude of the ship, describing the ship's roll, pitch, and yaw, respectively, as shown in Figure 3. It is assumed that the initial position of the ship-based coordinate system $O_{x 1 y 1 z 1}$ coincides with the global coordinate system $O_{x 0 y 0 z 0}$. After three rotations, it turns to a new position where the coordinate system is $O_{x y z}$. The relationship of the coordinate system variables between $O_{x 1 y 1 z 1}$ and $O_{\widehat{x y z}}$ can be gained according to the coordinate transformation matrix. Assume that $R_{x}, R_{y}$, and $R_{z}$ are the rotation matrices of hull about the axes $x, y$, and $z$. 


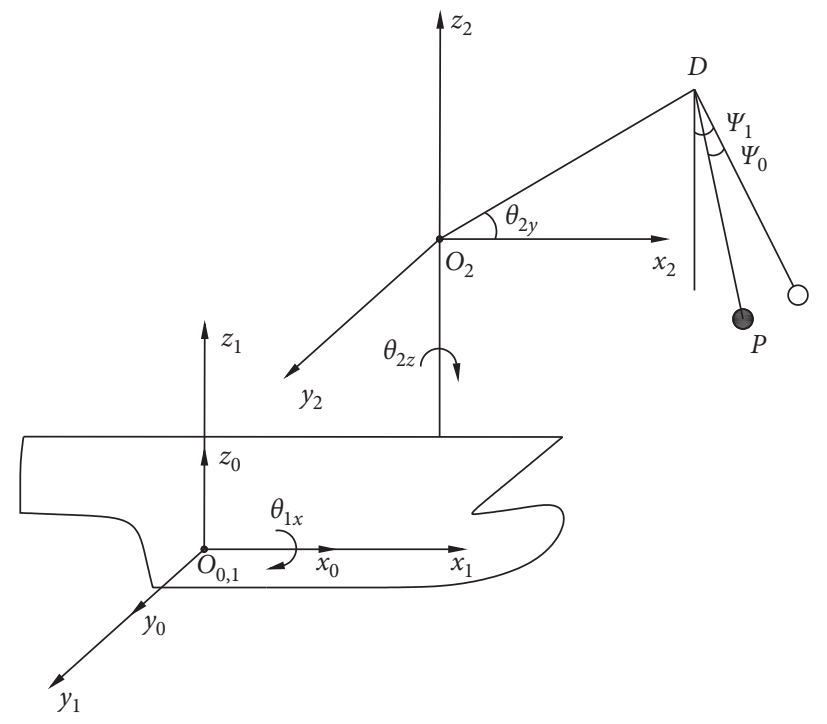

Figure 2: Ship crane schematic diagram.

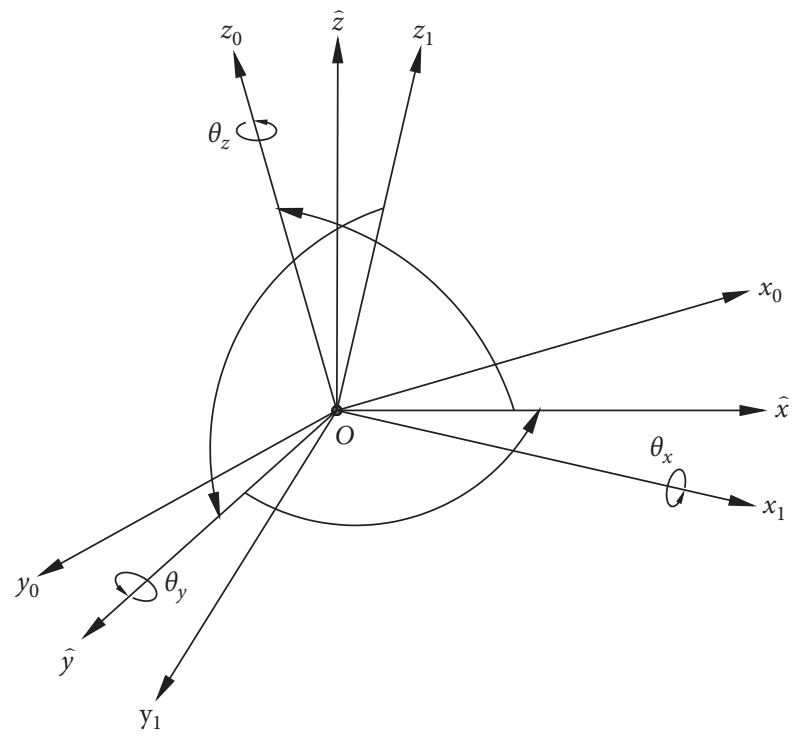

FIgURE 3: Ship motion Euler angle.

Then,

$$
\begin{aligned}
& R_{x}=\left[\begin{array}{ccc}
1 & 0 & 0 \\
0 & \cos \theta_{x} & \sin \theta_{x} \\
0 & -\sin \theta_{x} & \cos \theta_{x}
\end{array}\right], \\
& R_{y}=\left[\begin{array}{ccc}
\cos \theta_{y} & 0 & -\sin \theta_{y} \\
0 & 1 & 0 \\
\sin \theta_{y} & 0 & \cos \theta_{y}
\end{array}\right], \\
& R_{z}=\left[\begin{array}{ccc}
\cos \theta_{z} & \sin \theta_{z} & 0 \\
-\sin \theta_{z} & \cos \theta_{z} & 0 \\
0 & 0 & 1
\end{array}\right] .
\end{aligned}
$$

3.2. Kinetics Model of the Payload. The matrix of point $D$ relative to crane boom coordinate system is

$$
{ }^{2} P_{D}=\left[\begin{array}{c}
L_{\mathrm{O}_{2} D} \cos \theta_{2 y} \\
0 \\
L_{\mathrm{O}_{2} D} \sin \theta_{2 y}
\end{array}\right] .
$$

Define ${ }_{n}^{m} R$ as the rotation matrix from xnynzn to xmymzm; then,

$$
\begin{aligned}
& { }_{0}^{1} R=\left[\begin{array}{ccc}
1 & 0 & 0 \\
0 & \cos \theta_{1 x} & \sin \theta_{1 x} \\
0 & -\sin \theta_{1 x} & \cos \theta_{1 x}
\end{array}\right], \\
& { }_{0}^{2} R=\left[\begin{array}{ccc}
\cos \theta_{2 z} & \sin \theta_{2 z} & 0 \\
-\cos \theta_{1 x} \sin \theta_{2 z} & \cos \theta_{1 x} \cos \theta_{2 z} & \sin \theta_{1 x} \\
\sin \theta_{1 x} \sin \theta_{2 z} & -\sin \theta_{1 x} \cos \theta_{2 z} & \cos \theta_{1 x}
\end{array}\right] .
\end{aligned}
$$

The payload position relative to the global coordinate system is

$$
{ }^{0} P_{D}={ }^{0} P_{1}+{ }_{0}^{1} R{ }^{T} P_{2}+{ }_{0}^{2} R{ }^{T} P_{D}
$$

Among them, ${ }^{1} P_{2}=\left[\begin{array}{lll}L_{x} & L_{y} & L_{z}\end{array}\right]^{T}$ represents the position of $\mathrm{O}_{2}$ in $\mathrm{O}_{1 \times 1 y 1 z 1}$.

Substituting (4)-(7), the position of point $D$ in the global coordinate system can be obtained:

$$
{ }^{0} P_{D}=\left[\begin{array}{lll}
x_{D} & y_{D} & z_{D}
\end{array}\right]^{T} .
$$

The matrix of point $P$ relative to point $D$ is

$$
{ }^{D} P_{P}=\left[\begin{array}{c}
L_{P D} \cos \psi_{0} \sin \psi_{1} \\
-L_{P D} \sin \psi_{0} \\
-L_{P D} \cos \psi_{0} \cos \psi_{1}
\end{array}\right] .
$$

Among them, ${ }^{o} P_{P}={ }^{o} P_{D}+{ }^{D} P_{P}=\left[\begin{array}{lll}x_{P} & y_{P} & z_{P}\end{array}\right]^{T}$, and the acceleration of point $P$ is 


$$
\begin{aligned}
& \ddot{x}_{P}=\ddot{x}_{D}+L_{P D} \ddot{\psi}_{0} \cos \psi_{0}-L_{P D} \dot{\psi}_{0}^{2} \sin \psi_{0}, \\
& \ddot{y}_{P}=\ddot{y}_{D}+L_{P D} \cos \psi_{1}\left(\ddot{\psi}_{1} \cos \psi_{0}-2 \dot{\psi}_{0} \dot{\psi}_{1} \sin \psi_{0}\right)-L_{P D} \sin \psi_{1}\left(\cos \psi_{0}\left(\dot{\psi}_{1}^{2}+\dot{\psi}_{0}^{2}\right)+\ddot{\psi}_{0} \sin \psi_{0}\right), \\
& \ddot{z}_{P}=\ddot{z}_{D}+L_{P D}\left(\cos \psi_{1} \cos \psi_{0} \dot{\psi}_{1}^{2}-2 \dot{\psi}_{0} \dot{\psi}_{1} \sin \psi_{1} \sin \psi_{0}+\cos \psi_{1} \cos \psi_{0} \dot{\psi}_{0}^{2}+\ddot{\psi}_{1} \sin \psi_{1} \cos \psi_{0}+\ddot{\psi}_{0} \cos \psi_{1} \sin \psi_{0}\right) .
\end{aligned}
$$

3.3. 3D Dynamic Model of the Antiswing Device. The three spring dampers are mounted symmetrically in the cylinder of the antiswing device, and the coordinates can be easily obtained as $O(0,0), A(0, \mathrm{r}), B(-\sqrt{2} / 2 r,-\sqrt{2} / 2 r)$, and $C$ $(\sqrt{2} / 2 r,-\sqrt{2} / 2 r), r$ is the sleeve radius, when the telescopic sleeve comes from $\mathrm{O}$ to $\mathrm{O}^{\prime}$, the in-plane angle is defined as $\psi_{1}$, and the out-plane angle as $\psi_{0}$, as shown in Figure 4.

The length of each spring is

$$
\begin{aligned}
& \left|A O^{\prime}\right|=\sqrt{\left(L_{\mathrm{DE}} \sin \psi_{0}-0\right)^{2}+\left(L_{\mathrm{DE}} \cos \psi_{0} \sin \psi_{1}-r\right)^{2},} \\
& \left|B O^{\prime}\right|=\sqrt{\left(L_{\mathrm{DE}} \sin \psi_{0}+\sqrt{2} / 2 r\right)^{2}+\left(L_{\mathrm{DE}} \cos \psi_{0} \sin \psi_{1}+\sqrt{2} / 2 r\right)^{2}}, \\
& \left|C O^{\prime}\right|=\sqrt{\left(L_{\mathrm{DE}} \sin \psi_{0}-\sqrt{2} / 2 r\right)^{2}+\left(L_{\mathrm{DE}} \cos \psi_{0} \sin \psi_{1}+\sqrt{2} / 2 r\right)^{2}} .
\end{aligned}
$$

The force of each spring is

$$
\begin{aligned}
& \mathrm{SA}=k\left(\left|A O^{\prime}\right|-r\right) ; \\
& \mathrm{SB}=k\left(\left|B O^{\prime}\right|-r\right) ; \\
& \mathrm{SC}=k\left(\left|C O^{\prime}\right|-r\right),
\end{aligned}
$$

where $k$ is the spring stiffness coefficient, and SA, SB, and SC are the spring forces of $A, B$, and $C$ spring.

The force of each damping is

$$
\begin{aligned}
& \mathrm{DA}=c V_{A} ; \quad V_{A}=\frac{d\left(\left|A O^{\prime}\right|-r\right)}{d t} ; \\
& \mathrm{DB}=c V_{B} ; \quad V_{B}=\frac{d\left(\left|B O^{\prime}\right|-r\right)}{d t} ; \\
& \mathrm{DC}=c V_{C} ; \quad V_{C}=\frac{d\left(\left|C O^{\prime}\right|-r\right)}{d t},
\end{aligned}
$$

where $c$ is the damping coefficient, and DA, DB, and DC are the damping forces of $A, B$, and $C$ damping.

The direction components of the three spring dampers along $x$ axis and $y$ axis are

$$
\begin{aligned}
& i A_{x}=\frac{\left(L_{\mathrm{DE}} \sin \psi_{0}-0\right)}{\left|A O^{\prime}\right|} ; \\
& i A_{y}=\frac{\left(L_{\mathrm{DE}} \cos \psi_{0} \sin \psi_{1}-r\right)}{\left|A O^{\prime}\right|} ; \\
& i B_{x}=\frac{\left(L_{\mathrm{DE}} \sin \psi_{0}+\sqrt{2} / 2 r\right)}{\left|B O^{\prime}\right|} ; \\
& i B_{y}=\frac{\left(L_{\mathrm{DE}} \cos \psi_{0} \sin \psi_{1}+\sqrt{2} / 2 r\right)}{\left|B O^{\prime}\right|} ; \\
& i C_{x}=\frac{\left(L_{\mathrm{DE}} \sin \psi_{0}+\sqrt{2} / 2 r\right)}{\left|C O^{\prime}\right|} ; \\
& i C_{y}=\frac{\left(L_{\mathrm{DE}} \cos \psi_{0} \sin \psi_{1}-\sqrt{2} / 2 r\right)}{\left|C O^{\prime}\right|} .
\end{aligned}
$$

So

$$
\begin{aligned}
\mathrm{SF}_{X} & =\mathrm{SA} \cdot i A_{x}+\mathrm{SB} \cdot i B_{x}+\mathrm{SC} \cdot i C_{x} ; \\
\mathrm{SF}_{Y} & =\mathrm{SA} \cdot i A_{y}+\mathrm{SB} \cdot i B_{y}+\mathrm{SC} \cdot i C_{y} ; \\
\mathrm{DF}_{X} & =\mathrm{DA} \cdot i A_{x}+\mathrm{DB} \cdot i B_{x}+\mathrm{DC} \cdot i C_{x} ; \\
\mathrm{DF}_{Y} & =\mathrm{DA} \cdot i A_{y}+\mathrm{DB} \cdot i B_{y}+\mathrm{DC} \cdot i C_{y},
\end{aligned}
$$

where $\mathrm{SF}_{X}, \mathrm{SF}_{Y}$ are the components of spring force in $x$ axis and $y$ axis, and $\mathrm{DF}_{X}, \mathrm{SF}_{Y}$ are the components of damper force in $x$ axis and $y$ axis.

On the basis of D'Alembert principle, the moment of tangential inertia force relative to hinge point $O$ along $x$ axis and $y$ axis is 0 , so as to achieve torque balance of the telescopic sleeve.

The torque equilibrium equation is

$$
\left\{\begin{array}{l}
\sum M_{x}\left(F^{\tau}\right)=0, \\
\sum M_{y}\left(F^{\tau}\right)=0 .
\end{array}\right.
$$

Then, the spherical equation can be solved: 


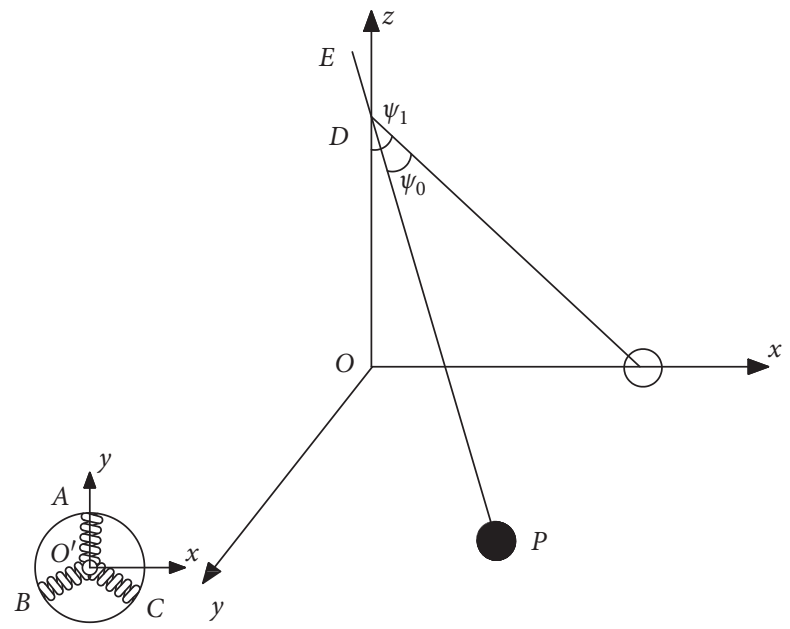

FIgURE 4: Payload swing diagram.

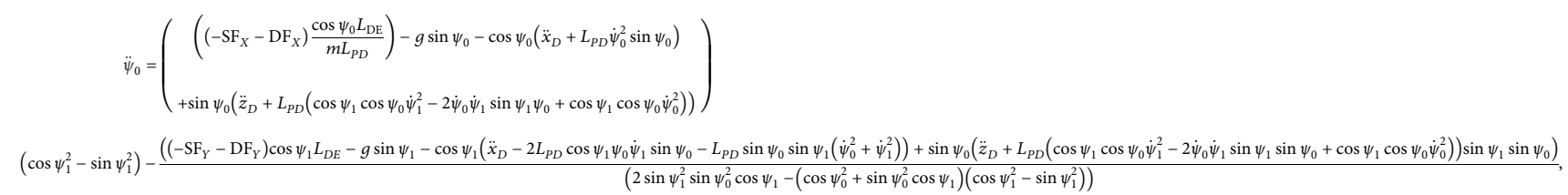

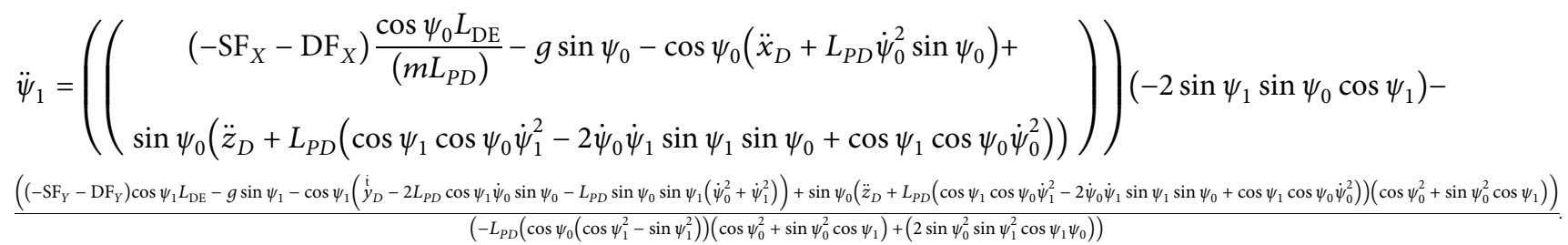

\section{Experiment}

In order to verify the dynamic model established in this study, a telescopic sleeve antiswing for shipboard crane experimental platform was built, as shown in Figure 5; the experimental platform is composed of the computer, electrical control cabinet, swing angle indicator, six-degree-offreedom platform, and crane body. When the load is swinging, the swing indicator is used to monitor the swing angle in real time, and the swing angle data are recorded. The main parameters are as follows: $m=5 \mathrm{~kg}, L_{z}=1.0 \mathrm{~m}$, $L_{\mathrm{O}_{2} D}=1.2 \mathrm{~m}, \quad L_{P D}=1.2 \mathrm{~m}, L_{E D}=0.1 \mathrm{~m}, \quad r=0.1 \mathrm{~m}, \quad$ and $g=9.81 \mathrm{~m} / \mathrm{s}^{2}$.

4.1. Verification of the Dynamic Model without the Antiswing Device. The initial swing angle is $4^{\circ}$, the spring damper in telescopic sleeve is removed, and 100 data of the swing angle are extracted within $15 \mathrm{~s}$; the comparison of the dynamic simulation value and the experimental value of the telescopic sleeve antiswing device is shown in Figure 6. The trend of the simulation value is basically consistent with the experimental value, and the curves change periodically, and the maximum error of the two curves is within $1 \%$, which verifies the correctness of the shipboard crane system dynamic model without the antiswing device. Because the measurement error of the swing angle and other external factors such as air resistance are not considered in theoretical analysis, there are some errors between the experimental value and the theoretical value.

4.2. Verification of the Dynamic Model with the Antiswing Device. The initial swing angle is $5^{\circ}$, the spring damping coefficient $C=250 \mathrm{Ns} / \mathrm{m}$, and 300 data of the swing angle are extracted within $50 \mathrm{~s}$; the comparison of the dynamic simulation value and the experimental value of the telescopic sleeve antiswing device is shown in Figure 7. The trend of simulation value is basically consistent with the experimental value in $0-30 \mathrm{~s}$ time interval, and the curves change periodically, which verifies the correctness of the shipboard crane system dynamic model with the antiswing device. But in $30 \mathrm{~s}-50 \mathrm{~s}$ time interval, the data overlap is not good; the reason is that the swing angle at this time is about \pm 0.5 degrees, and when the swing angle is such small, insufficient accuracy of equipment such as the swing angle indicator leads to errors in data recording. 


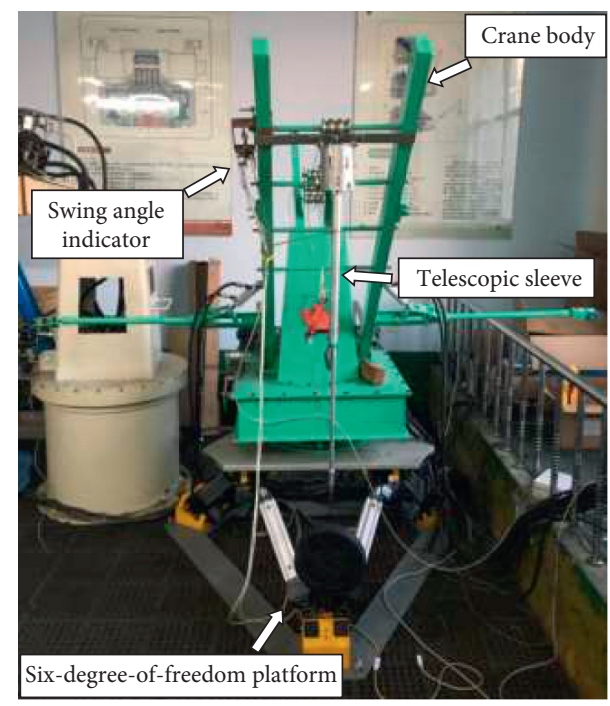

Figure 5: Experimental setup of the payload system.

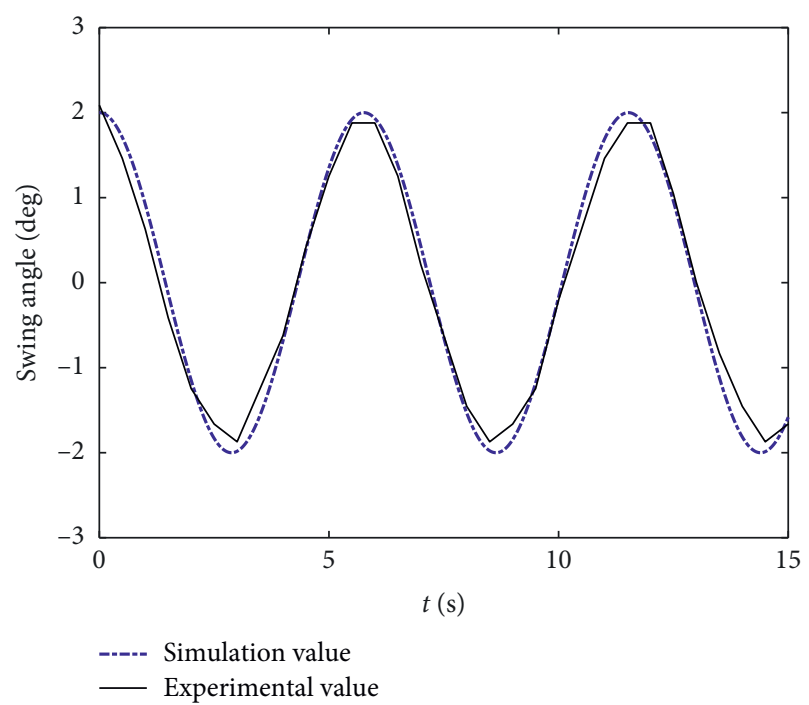

FIgURE 6: Comparison of in-plane angle curves without the antiswing device.

\section{Dynamic Analysis of the Crane System}

5.1. Influence of Sleeve Expansion and Contraction Amount on Payload Swing. The influence law of sleeve elongation on the payload swing without ship excitations is analyzed. Assuming the initial payload swing angle is $10^{\circ}$ and the damping of spring damper is 0 , the length of telescopic sleeve is treated as variable which is set as $0.5 \mathrm{~m}, 1.1 \mathrm{~m}, 1.5 \mathrm{~m}$, and $2.0 \mathrm{~m}$, respectively. Under these conditions, the payload swing is regular sinusoidal motion with the swing amplitude of $10^{\circ}$, and the simulation results are shown in Figure 8 . It can be concluded that the longer the sleeve is, the larger the swing period and the smaller the swing frequency is. In accordance with formula (21), the sleeve elongation is inversely proportional to the payload swing period, and the frequency will decrease with the increase of sleeve

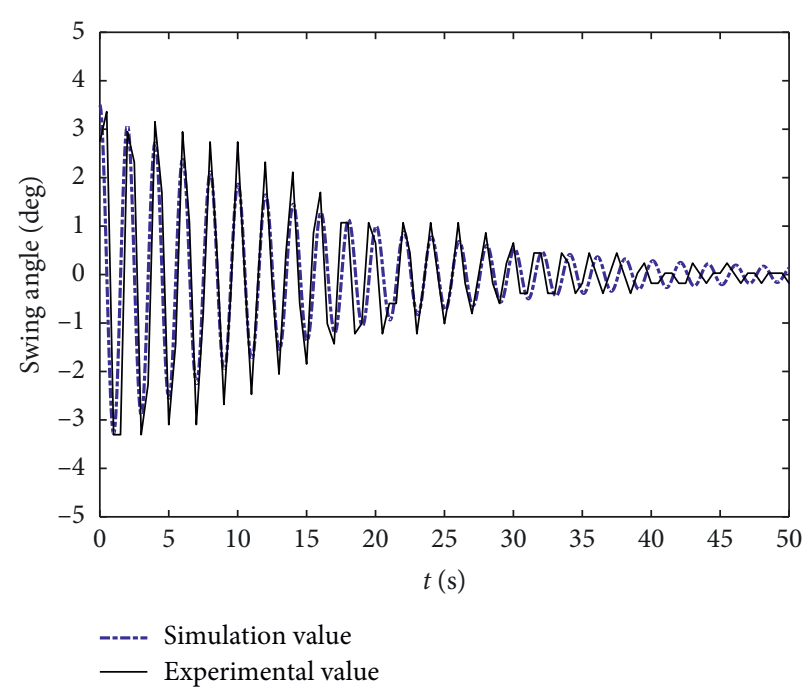

FIgURE 7: Comparison of in-plane angle curves with the antiswing device.

elongation. The simulation results are consistent with the theoretical formula analysis, which further verifies the correctness of the simulation.

The characteristic frequency of the antiswing device is

$$
\omega_{n}=\frac{1}{2 \pi} \sqrt{\frac{l}{g}}
$$

5.2. Influence of Ship's Roll on Payload Swing Angle. Assuming the sleeve elongation $l$ is constant, the influence of the ship's roll frequency on payload swing is analyzed, and the results are shown in Figure 9. It can be seen that the payload swing increases with the increase of ship's roll frequency, and when the ship's roll frequency is consistent with the characteristic frequency of the antiswing system, the payload swing will increase greatly. Therefore, the calculated comparison table between the characteristic frequency of the antiswing system and the ship's swing frequency should be included in ship operation manual, and instructions should be provided to the crane operators to avoid the resonance phenomenon.

5.3. Influence of Spring Damper Specifications on Payload Swing Angle. Assuming the initial payload swing angle is $10^{\circ}$, sleeve elongation is $1.08 \mathrm{~m}$, and the damping coefficient $C$ is 0 , the influence of different spring stiffness coefficients on payload swing angle is shown in Figure 10. With the increase of stiffness coefficient, the spring force increases, as shown in Figure 10(b), but the payload swing angle is not affected, as shown in Figure 10(a). In both cases, the payload swing amplitude is $10^{\circ}$ while the swing period remains unchanged. It can be deduced that in the case when spring exists but without damper, no matter how the spring stiffness coefficient is changed, the antiswing device would have no effect on the payload swing reduction. 


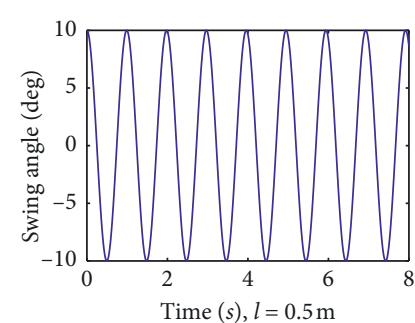

(a)

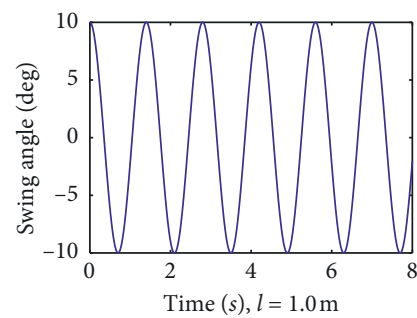

(b)

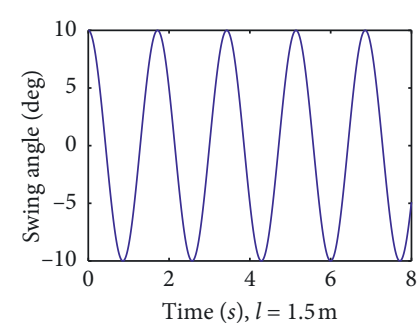

(c)

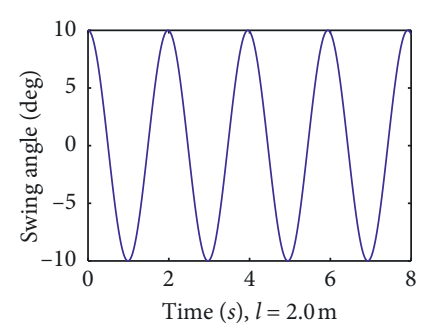

(d)

FIgURE 8: Influence of sleeve expansion and contraction.

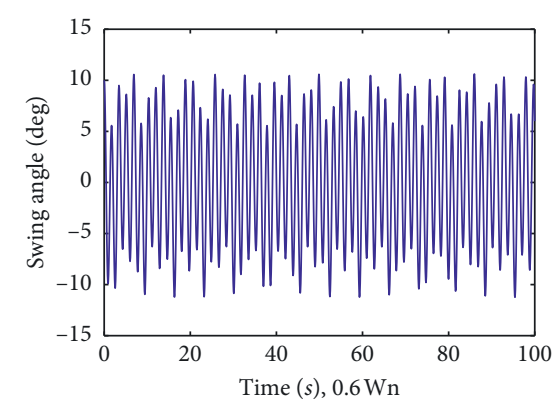

(a)

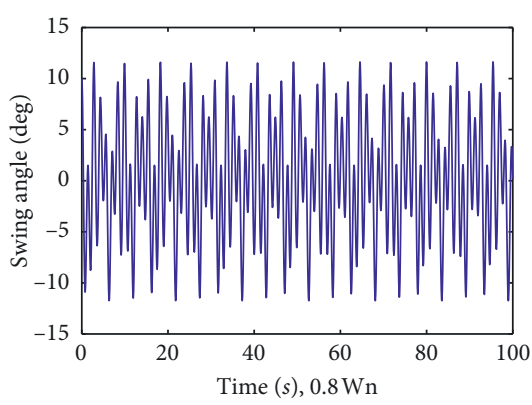

(b)

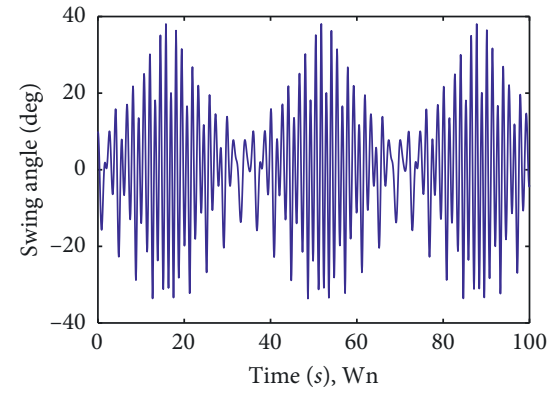

(c)

FIgURE 9: Influence of ship's rolling frequency.

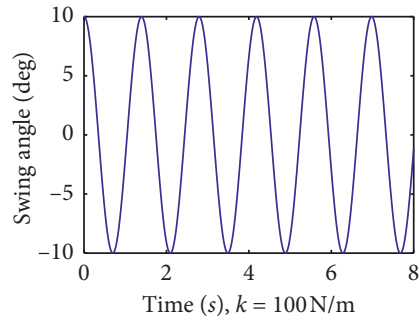

(a)

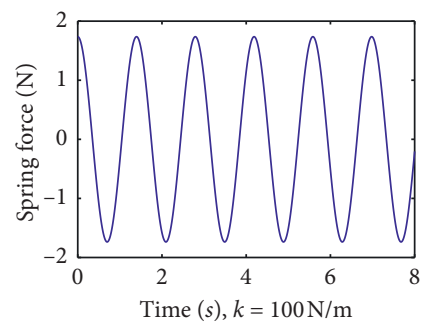

(c)

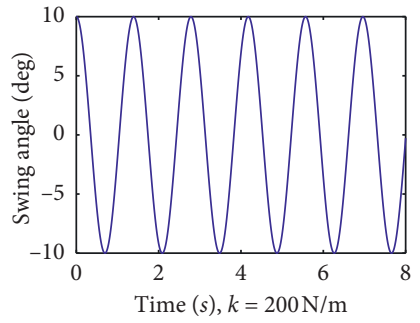

(b)

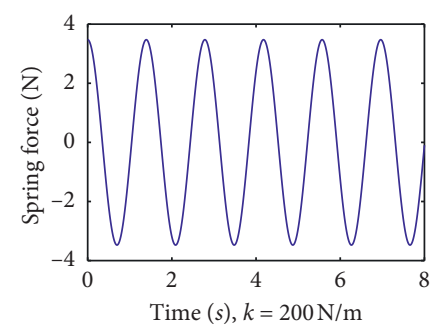

(d)

FIGURE 10: Influence of spring constant. (a) Swing amplitude with different stiffness coefficients. (b) Spring force with different stiffness coefficients.

When the spring coefficient is constant, i.e., $K=100 \mathrm{~N} / \mathrm{m}$, the influence of different damping coefficients on the payload swing can be seen as shown in Figure 11. The larger the damping coefficient is, the faster the swing angle decays and the shorter the swing angle decays to 0 . Otherwise, the decay speed of the swing angle becomes slower as the damping coefficient becomes smaller. The swing angle decays for more than 10 seconds when the damping coefficient $C<1000 \mathrm{Ns} / \mathrm{m}$, the time for payload swing angle decay to 0 is less than $6 \mathrm{~s}$ when $C>1500 \mathrm{Ns} / \mathrm{m}$, and when $C>2000 \mathrm{Ns} / \mathrm{m}$, the time for payload swing angle decay to 0 is less than $4 \mathrm{~s}$. After 


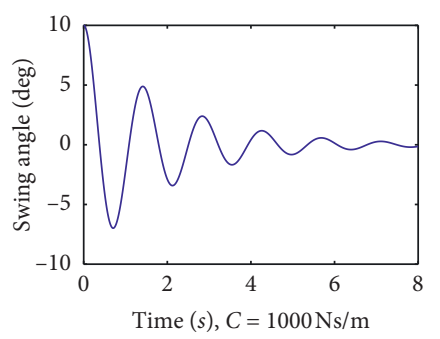

(a)

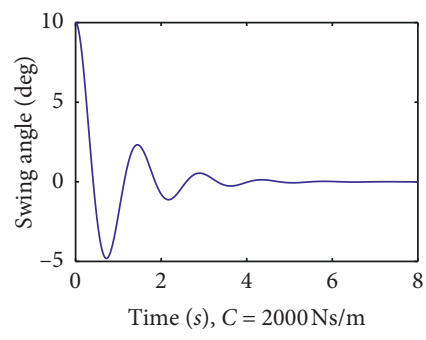

(c)

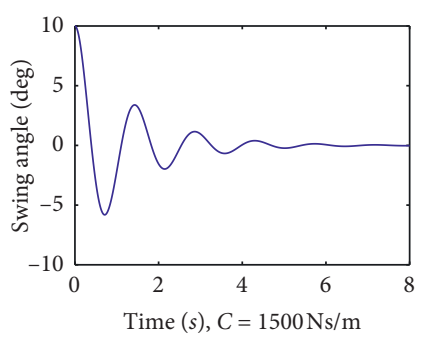

(b)

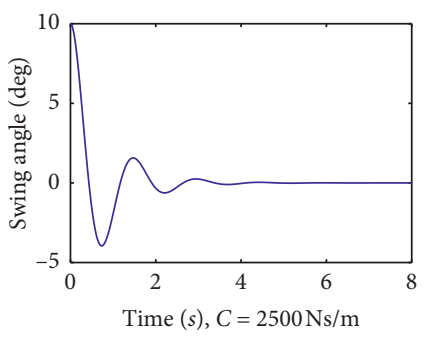

(d)

FIgURE 11: Influence of damping change on payload swing.

calculation, in order to make the payload swing attenuate to 0 in a reasonable time, the applicable range of the damper coefficient suitable for this experimental platform is $C=1500 \sim 2000 \mathrm{Ns} / \mathrm{m}$.

\subsection{Influence of Ship's Roll on Payload Swing Angle with} Damper. Assume the initial in-plane swing angle of the payload is $20^{\circ}$, the spring stiffness coefficient $K$ is $200 \mathrm{~N} / \mathrm{m}$, and the damping coefficient $C$ is $2000 \mathrm{Ns} / \mathrm{m}$. The influence of ship's roll on payload swing with the telescopic sleeve antiswing device is shown in Figure 12. Under the effect of the antiswing device, the swing of the telescopic sleeve is gradually attenuated by the spring damper in $4 \mathrm{~s}$. Despite the swing angle is greatly reduced, it still has a residual swing angle of $2^{\circ}$. As observed, the spring force and damping force of the antiswing device also decrease with the decrease of payload swing angle.

\subsection{Influence of Ship's Pitch on Payload Swing Angle with} Damper. Suppose the initial out-plane swing angle of the payload is $20^{\circ}$, the spring stiffness coefficient $K$ is $200 \mathrm{~N} / \mathrm{m}$, and the damping coefficient $C$ is $2000 \mathrm{Ns} / \mathrm{m}$; the impact of ship's pitch on the payload swing of the crane with the telescopic sleeve antiswing device is shown in Figure 13. The payload swing characteristics are similar to those under ship's roll condition, and the swing cannot be completely stopped by the antiswing device, but the residual swing amplitude is obviously larger than that under ship's roll condition. This is because the ship's pitch or roll axis passes through the ship's float center, and the farther the crane base is from the float center, the larger the payload swing angle is. Therefore, in order to reduce the payload swing angle, the crane base should be arranged as close as possible to ship's float center coordinates under working conditions, so as to minimize the influence of ship shaking on payload swing.
5.6. Influence of Ship's Roll and Pitch on Payload Swing Angle with Three Dampers. Given the initial in-plane angle $\psi_{1}=20^{\circ}$, out-plane angle $\psi_{0}=10^{\circ}$, the spring stiffness coefficient $K=100 \mathrm{~N} / \mathrm{m}$, and the damping coefficient $C=1500 \mathrm{~ns} / \mathrm{m}$. When the ship's roll and pitch is coupled, the impact on payload swing with the telescopic sleeve antiswing device is shown in Figure 14. Under the effect of the antiswing device, the in-plane angle and out-plane angle of the payload will rapidly and greatly attenuate, wherein the inplane angle reduced to $3^{\circ}$ with a reduction of $70 \%$, and outplane angle reduced to $1^{\circ}$ with a reduction of $90 \%$.

The three spring dampers in the cylinder of the antiswing device are distributed at an angle of $120^{\circ}$, as shown in Figure 4 . The three spring forces and damping forces will also decrease with the decrease of payload swing angle. Because of the geometric distribution, the stress of the three spring dampers is quite different, as shown in Figure 15. The smaller the angle with respect to payload swing plane, the greater the stress of the spring damper. Therefore, in engineering, if the payload swing plane is within a certain range, the cylinder of the antiswing device should be rotated regularly to make time of the spring dampers bearing extreme force evenly, so as to avoid fatigue failure caused by excessive concentrated use of a spring damper.

5.7. Influence of Ship's Heeling on Payload Swing. When the shipboard crane lifts the payload away or changes its position, the floating state and initial stability of the ship will change, thus affecting the response law of payload swing. Assume the payload is lifted with weight $G$ on board from point $A$ (abscissa $y_{A}$ ) on the port side to point $A_{1}$ (abscissa $\left.y_{B}\right)$ on the starboard side in the horizontal direction. The moving distance is $\left(y_{A}-y_{B}\right)$, and the roll angle is $\varphi$, as shown in Figure 16. The position of metacentric $M$ is constant, the shift of payload causes ship's gravity center to move laterally 


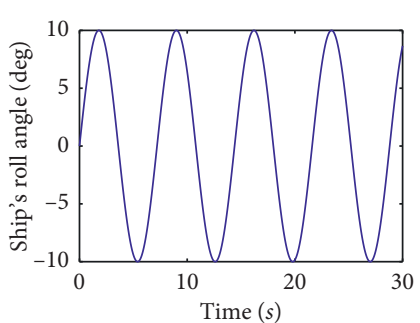

(a)

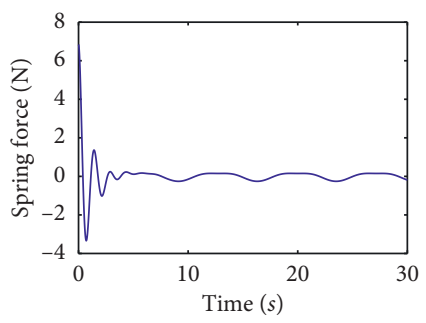

(c)

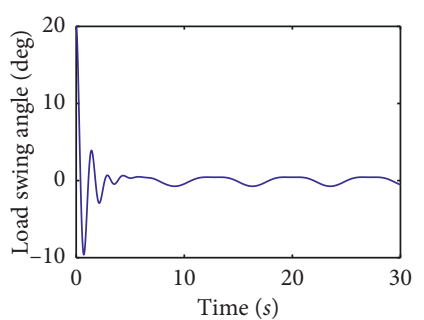

(b)

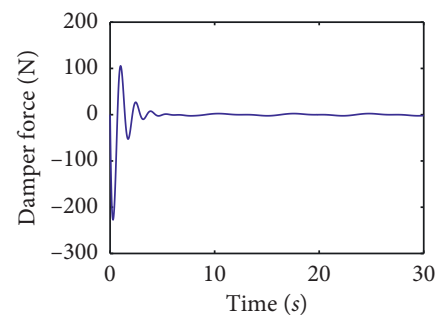

(d)

Figure 12: Influence of ship's roll on payload swing.

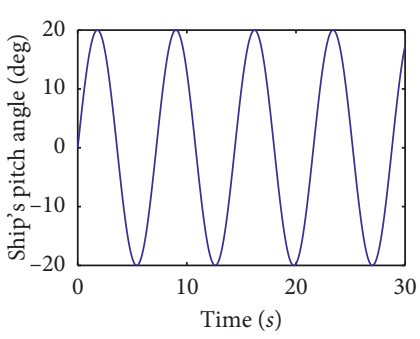

(a)

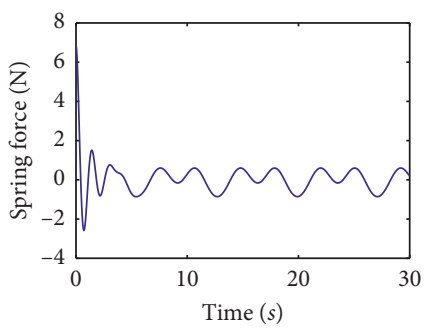

(c)

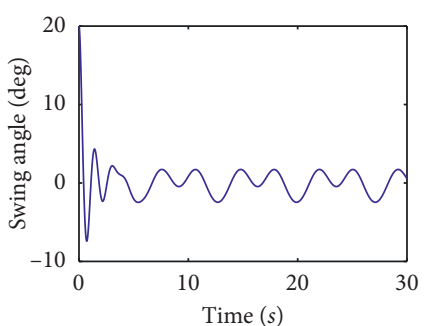

(b)

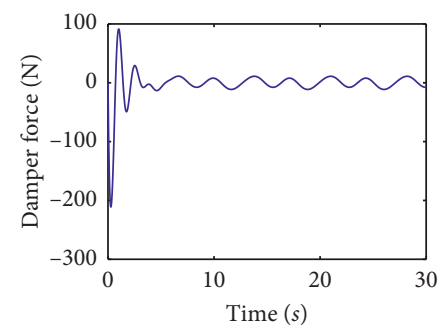

(d)

FIGURE 13: Influence of ship's pitch.

from the original $G$ point to $G_{1}$ point, and the buoyancy center $B$ moves laterally to $B_{1}$.

New initial stability is

$$
\overline{G_{1} M}=\overline{G M}+\frac{m\left(y_{A}-y_{B}\right)}{\Delta} .
$$

Tangent of ship's heel angle is

$$
\tan \varphi=\frac{m\left(y_{A}-y_{B}\right)}{\left(\Delta \overline{G_{1} M}\right)} .
$$

It can be seen from equations (22) and (23) that when the position of the payload changes, the stability and floating state of the ship are influenced. Assume that the ship's roll angle $\varphi$ is $3^{\circ}$ or $5^{\circ}$, due to the shift of the payload position, and its influence on payload swing is shown in Figure 16. Suppose that the payload initial swing angle is $5^{\circ}$, when the position change of the payload causes a $3^{\circ}$ roll angle of the ship, the payload swing amplitude increases from $5^{\circ}$ to $8^{\circ}$ as shown in Figure 17(a). When the ship's roll angle is $5^{\circ}$, the swing angle increases from $5^{\circ}$ to $10^{\circ}$ as shown in Figure 17(b). Therefore, the change of ship's roll angle will lead to the change of payload swing amplitude, but the swing period will not change.

5.8. Influence of Payload Swing on Ship Stability. When the ship inclines, the payload swing will adversely affect the stability. $\overline{\mathrm{GM}}$ represents the initial stability of the ship, $G$ 


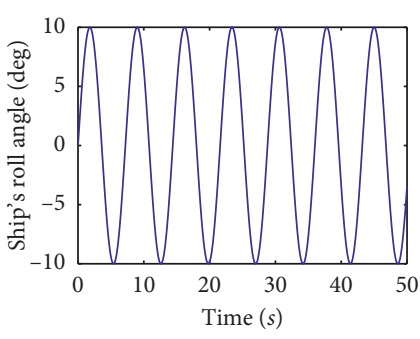

(a)

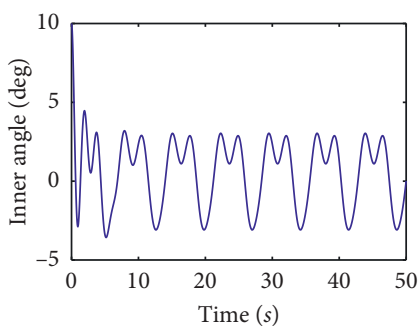

(c)

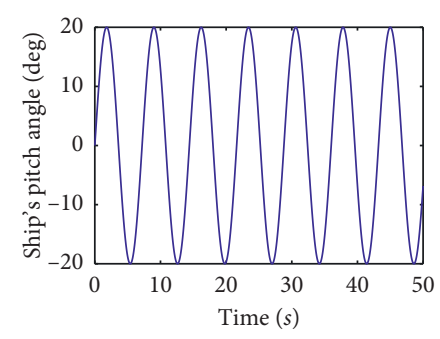

(b)

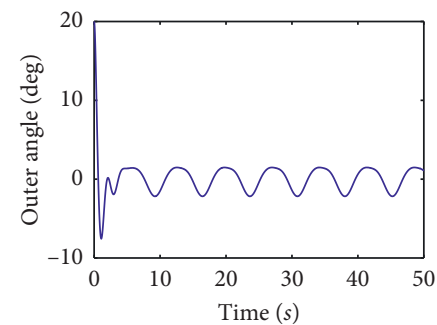

(d)

FIGURE 14: Influence of ship's roll and pitch on swing.

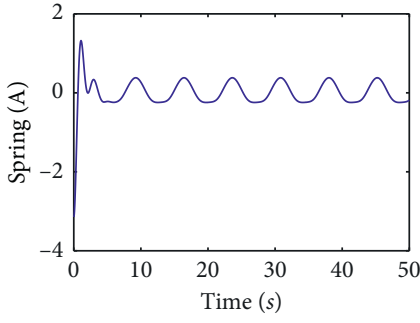

(a)

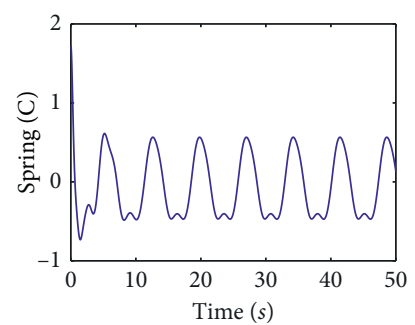

(c)

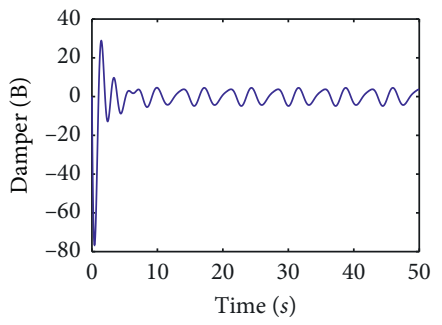

(e)

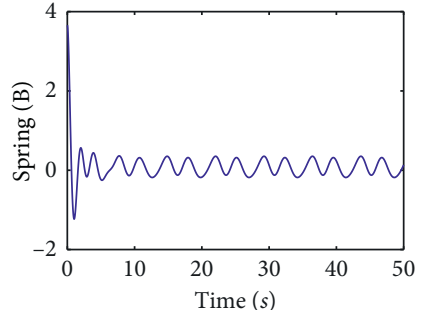

(b)

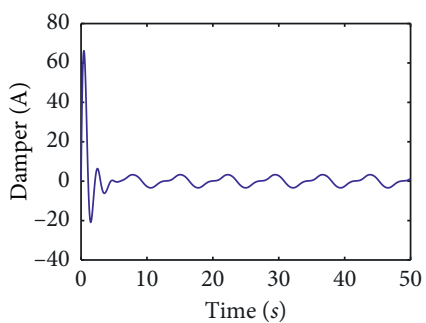

(d)

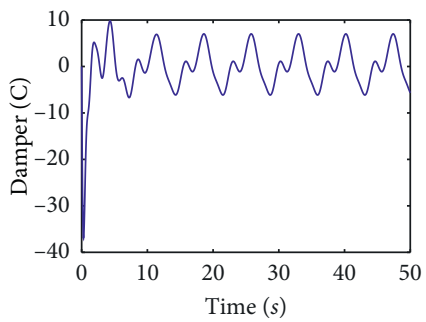

(f)

FIGURE 15: Influence of ship's roll and pitch on spring damper. 


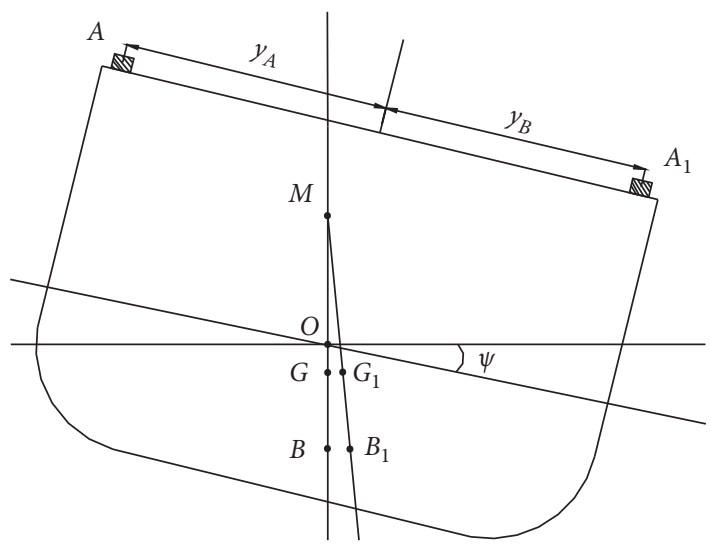

FIGURE 16: Transverse horizontal displacement of the load.

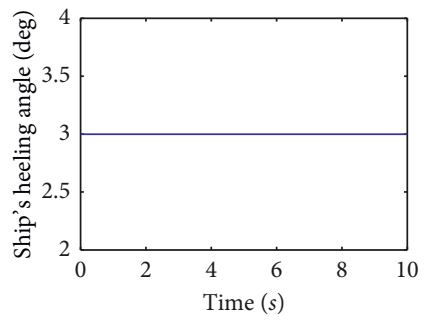

(a)

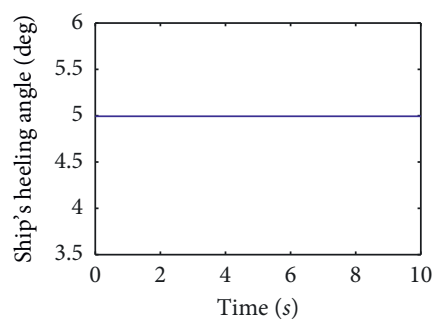

(c)

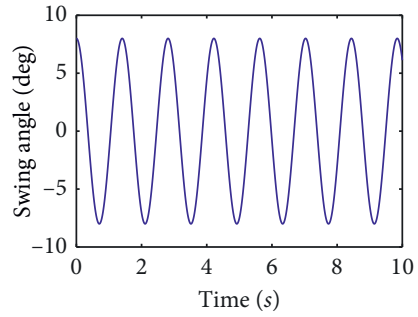

(b)

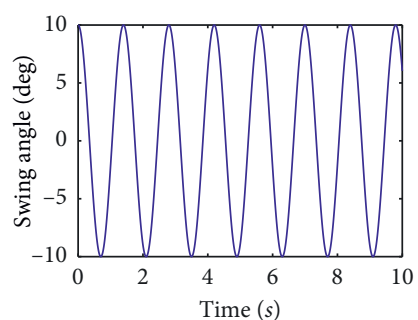

(d)

Figure 17: Influence of payload position on payload swing. (a) Influence of ship's roll on the payload swing $\left(\varphi=3^{\circ}\right)$. (b) Influence of ship's roll on the payload swing $\left(\varphi=5^{\circ}\right)$.

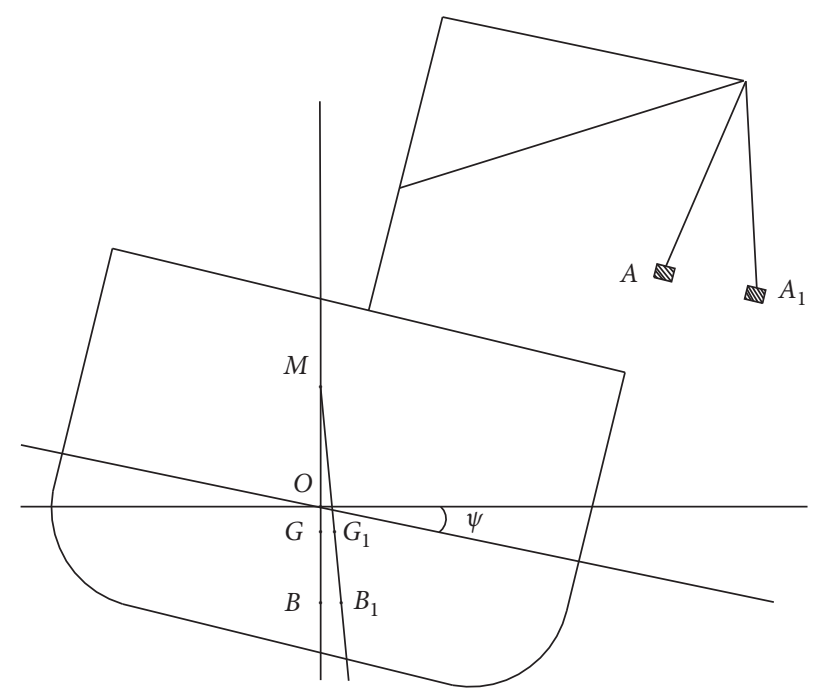

FIGURE 18: Influence of lifting payload on stability. 


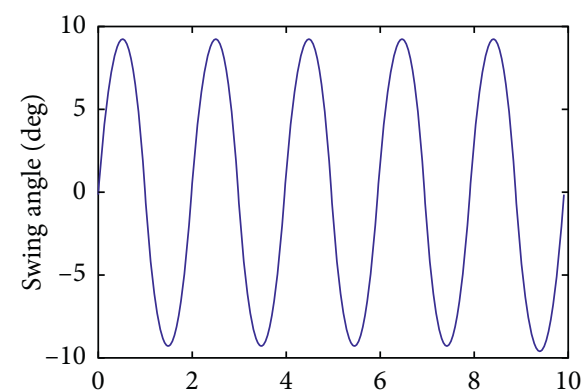

(a)

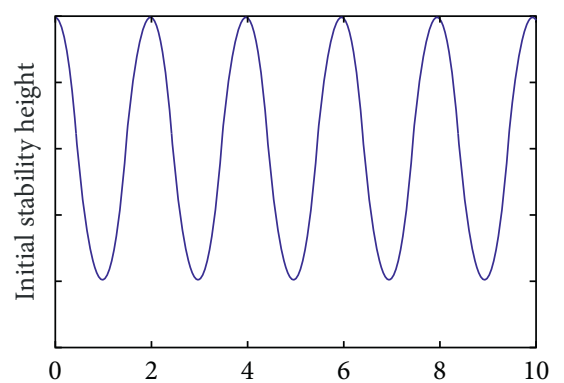

(b)

FIGURE 19: Change of stability with time.

refers the weight of the payload, $L$ is the length of the hoisting rope, and $\Delta$ is the ship displacement. When the payload is lifted away from ship, the ship tilts at a small angle $\varphi$, as shown in Figure 18.

The actual stability of the ship is

$$
\overline{G_{1} M}=\overline{\mathrm{GM}}-\frac{G l}{\Delta} .
$$

The ship stability changes with payload swing. It can be seen from equation (24), due to the change of the payload position, the ship's stability reduces GL/ $\Delta$ and the rolling caused by payload swing reduces the initial stability. As shown in Figure 19, from the corresponding relationship between payload swing angle and stability, when the payload swing angle reaches its maximum value, the initial stability gets to its minimum. When the payload swing angle is 0 (the ship returns to the equilibrium position), the stability reaches its maximum value. Therefore, when the payload is swung to one side, the ship may capsize under certain extreme conditions. Therefore, in engineering, under the condition of extreme weather or ship's large inclination in loading conditions, when the shipboard crane is lifting the payload, it is necessary to avoid the large swing of the payload. Meanwhile, the crane operations should be carried out strictly complying with the loading manual, and the calculation of the loading computer should be always monitored to ensure that the ship has sufficient stability.

\section{Conclusions}

(1) In this study, a 3D dynamic model of the system containing the ship, crane, antiswing device, and payload is established, which can truly simulate the swing characteristics of payload. Comparing with experimental data, the accuracy of the dynamic model is further verified.

(2) According to the calculation results, when the crane system is fixed, the reduction effect of payload swing is related to the damper parameters, and the appropriate damping coefficient can ensure that the payload swing be reduced in a short time. When the ship shaking frequency is consistent with the payload swing frequency, resonance will occur.

(3) The dynamic simulation results show that the telescopic sleeve antiswing device has a good antiswing effect under the coupled conditions of ship's roll and pitch and has a strong antiswing effect on the inplane angle and out-plane angle, which are reduced by about $70 \%$ and $90 \%$, respectively.

(4) The simulation results show that the ship's roll can lead to the increase of payload swing, and the payload swing has an adverse effect on ship stability.

(5) The antiswing characteristics of the telescopic sleeve antiswing device for shipboard crane were tested through experiments, and the correctness of the antiswing device dynamic model was verified by comparing the simulation value with the experimental value.

The research results of this study lay a foundation for the engineering applicability calculation and experiment of the telescopic sleeve antiswing device. At the same time, the dynamic modeling method can be used for reference in the research of antiswing problems for marine fan installation, offshore hoisting operation, and other engineering antiswing problems. Also, it establishes a basis for the structural optimization design of the telescopic sleeve antiswing device in next step.

\section{Data Availability}

The data used to support the findings of this study are included within the article and are available from the corresponding author upon request.

\section{Conflicts of Interest}

The authors declare that they have no conflicts of interest.

\section{Acknowledgments}

This study was funded by the National Key Research and Development Program of China (2018YFC0309003) and the 
Fundamental Research Funds for the Central Universities (3132019368).

\section{References}

[1] Z. Li, Nonliner Control for Two Types of Underactuated Systems, School of Control Science and Engineering Shandong University, Jinan, China, 2020.

[2] J. J. Wang and Y. S. Huang, "The motion response of a crane ship in a hoisting operation," China Ship Research, vol. 8, no. 3, pp. 51-56, 2013.

[3] J. C. Xu, Research on the Detection and Anti-Swing Control of Cranes on Offshore Transfer Platform Cranes, Jiangsu University, Zhenjiang, China, 2016.

[4] A. Huster, H. Bergstrom, J. Gosior, and D. White, "Design and operational performance of a standalone passive heave compensation system for a work class ROV," in Proceedings of the Oceans 2009, pp. 1-8, Biloxi, MS, USA, October 2009.

[5] W. Quan, Y. Liu, A. Zhang, X. Zhao, and X. Li, "The nonlinear finite element modeling and performance analysis of the passive heave compensation system for the deep-sea tethered ROVs," Ocean Engineering, vol. 127, pp. 246-257, 2016.

[6] D. B. Zhang and J. Wu, "Modeling and simulation of ship crane heave compensation system," China Mechanical Engineering, vol. 23, no. 7, pp. 794-797, 2012.

[7] J. T. Hatleskog and M. W. Dunnigan, "An impedance approach to reduce the contact-instability whilst drilling with active heave compensation," Ocean Engineering, vol. 49, pp. 25-32, 2012.

[8] S. Küchler, T. Mahl, J. Neupert, K. Schneider, and O. Sawodny, "Active control for an offshore crane using prediction of the vessel's motion," IEEE/ASME Transactions on Mechatronics, vol. 16, no. 2, pp. 297-309, 2011.

[9] M. Richter, S. Schaut, D. Walser, K. Schneider, and O. Sawodny, "Experimental validation of an active heave compensation system: estimation, prediction and control," Control Engineering Practice, vol. 66, pp. 1-12, 2017.

[10] W. Quan, Y. Liu, Z. Zhang, X. Li, and C. Liu, "Scale model test of a semi-active heave compensation system for deep-sea tethered ROVs," Ocean Engineering, vol. 126, pp. 353-363, 2016.

[11] S. Li, J. Wei, K. Guo, and W.-L. Zhu, "Nonlinear robust prediction control of hybrid active-passive heave compensator with extended disturbance observer," IEEE Transactions on Industrial Electronics, vol. 64, no. 8, pp. 6684-6694, 2017.

[12] W. C. Jin and Y. S. Liu, "Semi-active heave compensation based on servo-valve-controlled asymmetric servo-cylinder," Chinese Hydraulics and Pneumatics, vol. 4, pp. 37-41, 2017.

[13] M. Y. Chen and J. W. Ye, "Experimental study on a stable platform system having the function of wave motion compensation," Machine Tool \& Hydraulics, vol. 36, no. 4, pp. 67-70, 2008.

[14] D. H. Lu and W. C. Gao, "Design and simulation of active heave compensation platform and test system," Ship Engineering, vol. 37, no. 11, pp. 40-43, 2015.

[15] Y. P. Hu, Research on Key Technologies of Design and Control of Parallel Weave Compensation System with Six DOFs, National University of Defense Technology, Changsha, China, 2015.

[16] R. Dong, Key Technologies on Design of Cotrolling Systems for Active Heave Compensation, National University of Defense Technology, Changsha, China, 2009.

[17] P. A. J. Jardim, J. T. Rein, Ø. Haveland, and T. J. Impelluso, "Modeling crane-induced ship motion using the moving frame method," Journal of Offshore Mechanics and Arctic Engineering-Transactions of the ASME, vol. 141, no. 5, p. 11, 2019.

[18] B. Rong, X. Rui, K. Lu, L. Tao, G. Wang, and F. Yang, "Dynamics analysis and wave compensation control design of ship's seaborne supply by discrete time transfer matrix method of multibody system," Mechanical Systems and Signal Processing, vol. 128, pp. 50-68, 2019.

[19] V. T. Nguyen, K. D. H. Thi, V. A. Le, T. D. Pham, H. T. Vo, and Q. T. Pham, "Modeling and integral hierarchical slidingmode control for 2D ship-mounted crane," in Proceedings of the 2019 First International Symposium on Instrumentation, Control, Artificial Intelligence, and Robotics (ICA-SYMP 2019), pp. 82-85, Bangkok, Thailand, January 2019.

[20] X. G. Li, Z. Q. Mei, D. Zhu, and B. Xie, "Modeling and antisway control of ship-mounted crane," Advances in Mechanical Engineering, vol. 9, no. 9, Article ID 168781401772725, 2017.

[21] S. Wang, Y. Sun, H. Chen, and G. Han, "Kinematics and force analysis of a novel offshore crane combined compensation system," in Proceedings of the Institution of Mechanical Engineers, Part M: Journal of Engineering for the Maritime Environment, vol. 231, no. 2, pp. 633-648, 2017.

[22] W. Lv, L. W. Tao, and Z. Ji, "Research on anti-swing characteristic of redundancy cable-driven parallel robot," in Proceedings of the 2017 IEEE 2nd Advanced Information Technology, Electronic and Automation Control Conference Conference (IAEAC), pp. 1504-1508, Chongqing, China, March 2017.

[23] Y. F. Mao, "Anti-rolling control method of marine crane machinery," Ship Science and Technology, vol. 40, no. 3A, pp. 37-39, 2018.

[24] L. L. Li and Q. X. Qiu, "Research on dynamic analysis of shipcrane hoist system," Ship Science and Technology, vol. 40, no. 10, pp. 140-142, 2018.

[25] G. D. Han, T. Zhang, H. Chen, Z. Jin-Nan, and W.-Q. Duan, "Sling tray mechanical anti-swing system simulation and modeling of ship-mounted crane," in Proceedings of the 2017 2nd International Conference on Mechanical, Manufacturing, Modeling and Mechatronics (IC4M 2017), vol. 104, Kortrijk, Belgium, February 2017.

[26] N. Sun, Y. Fang, H. Chen, Y. Fu, and B. Lu, "Nonlinear stabilizing control for ship-mounted cranes with ship roll and heave movements: design, analysis, and experiments," IEEE Transactions on Systems, Man, and Cybernetics: Systems, vol. 48, no. 10, pp. 1781-1793, 2018.

[27] C. Chin, A. H. Nayfeh, and E. Abdel-Rahman, "Nonlinear dynamics of a boom crane," Journal of Vibration and Control, vol. 7, no. 2, pp. 199-220, 2001.

[28] C. Chin, A. H. Nayfeh, and D. T. Mook, "Dynamics and control of ship-mounted cranes," Journal of Vibration \& Control Jvc, vol. 7, no. 6, pp. 891-904, 2013.

[29] Q. H. Ngo, N. P. Nguyen, C. N. Nguyen, T. H. Tran, and V. H. Bui, "Payload pendulation and position control systems for an offshore container crane with adaptive-gain sliding mode control," Asian Journal of Control, vol. 22, no. 5, pp. 2119-2128, 2020.

[30] T. Yang, N. Sun, H. Chen, and Y. Fang, "Neural networkbased adaptive antiswing control of an underactuated shipmounted crane with roll motions and input dead zones," IEEE Transactions on Neural Networks and Learning Systems, vol. 31, no. 3, pp. 901-914, 2020.

[31] L. A. Tuan, Q. Ha, and V. T. Pham, "Observer-based nonlinear robust control of floating container cranes subject to output 
hysteresis," Journal of Dynamic Systems Measurement and Control, vol. 141, no. 11, 2019.

[32] L. A. Tuan, H. M. Cuong, P. V. Trieu, L. C. Nho, V. D. Thuan, and L. V. Anh, "Adaptive neural network sliding mode control of shipboard container cranes considering actuator backlash," Mechanical Systems and Signal Processing, vol. 112, pp. 233-250, 2018.

[33] Y.-Z. Qian, Y.-C. Fang, and T. Yang, "An energy-based nonlinear coupling control for offshore ship-mounted cranes," International Journal of Automation and Computing, vol. 15, no. 5, pp. 570-581, 2018.

[34] Y. Z. Qian, Y. C. Fang, and B. Lu, "Adaptive robust tracking control for an offshore ship-mounted crane subject to unmatched sea wave disturbances," Mechanical Systems and Signal Processing, vol. 141, pp. 566-570, 2019.

[35] N. P. Nguyen, Q. H. Ngo, and Q. P. Ha, "Active control of an offshore container crane," in Proceedings of the International, IEEE Conference on Control, Automation and Systems, pp. 773-778, Busan, South Korea, October 2015.

[36] X. Wu, Reasearch on Partial Feedback Linearization Control of Overhead Crane Systems, Zhejiang University of Technology, Hangzhou, China, 2016.

[37] F. Panuncio, W. Yu, and X. Li, "Stable neural PID anti-swing control for an overhead crane," Intelligent Automation \& Soft Computing, vol. 20, no. 2, pp. 145-158, 2014.

[38] T. Wang and J. Qiu, "Design of fuzzy PID controllers for twodimensional bridge cranes based on damping force," Journal of Wuyi University (Natural Science Edition), vol. 34, no. 3, pp. 47-53, 2020.

[39] T. Yang, N. Sun, H. Chen, and Y. Fang, "Neural networkbased adaptive antiswing control of an underactuated shipmounted crane with roll motions and input dead zones," IEEE Transactions on Neural Networks and Learning Systems, vol. 31, no. 3, pp. 901-914, 2020.

[40] N. Sun, T. Yang, H. Chen, and Y. Fang, "Dynamic feedback antiswing control of shipboard cranes without velocity measurement: theory and hardware experiments," IEEE Transactions on Industrial Informatics, vol. 15, no. 5, pp. 2879-2891, 2019.

[41] Z. Ren, R. Xi, S. Wang, Z. Zhang, and H. Chen, "Design of triple-cables limiting-location anti-swing device for shipboard crane," Journal of Shandong University (Engineering Science), vol. 50, no. 3, pp. 125-142, 2020.

[42] B. van Albada, G. Dick van Albada, H. Petter Hildre, and H. Zhang, "A novel approach to anti-sway control for marine shipboard cranes," in Proceedings of the 27th European Conference on Madeling and Simulation ECMS, Alesund, Norway, May 2013.

[43] S. Wang, Y. Sun, H. Chen, and J. Du, "Dynamic modelling and analysis of 3-axis motion compensated offshore cranes," Ships and Offshore Structures, vol. 13, no. 3, pp. 265-272, 2018.

[44] H. Chen and S. Wang, "Telescopic sleeve anti-swing device for marine cranes," vol. 5, Chinese Patent, 2014.

[45] G. Han, H. Li, H. Chen, Y. Sun, J. Zhang, and S. Wang, "Principle and kinetics modeling analysis of telescopic sleeve stabilizer of new offshore crane based on Adams," Machine Tool and Hydraulics, vol. 45, no. 3, pp. 149-153, 2017.

[46] Y. Cao and T. Li, "Review of antiswing control of shipboard cranes," IEEE/CAA Journal of Automatica Sinica, vol. 7, no. 2, pp. 346-354, 2020.

[47] B. Kimiaghalam, A. Homaifar, and M. Bikdash, "Feedback and feed forward control law for a ship crane with Mayland rigging system," in Proceedings of the 2000 IEEE American
Control Conference, vol. 2, pp. 1047-1051, Chicago, IL, USA, June 2000.

[48] B. Kimiaghalam, A. Homaifar, M. Bikdash, and B. R. Hunt, "Feedforward control law for a shipboard crane with Maryland rigging system," Journal of Vibration and Control, vol. 8, no. 2, pp. 159-188, 2002.

[49] B. Wen, A. Homaifar, M. Bikdash, and B. Kimiaghalam, "Modeling and optimal control design of shipboard crane," in Proceedings of the 1999 IEEE American Control Conference, vol. 1, pp. 593-597, San Diego, CA, USA, June 1999.

[50] B. Kimiaghalam, A. Homaifar, and M. Bikdash, "Pendulation suppression of a shipboard crane using fuzzy controller," in Proceedings of the 1999 IEEE American Conrol Conference, vol. 1, pp. 586-590, San Diego, CA, USA, June 1999.

[51] R. Zhu and M. Guoping, The Theory of Ship Motion on Waves, Shanghai Jiaotong University Press, Shanghai, China, 2019. 